NBER WORKING PAPER SERIES

TAXATION OF ASSET INCOME

IN THE PRESENCE OF A

WORLD SECURITIES MARKET

Roger H. Gordon

Hal R. Varian

Working Paper No. 1994

NATIONAL BUREAU OF ECONOMIC RESEARCH

1050 Massachusetts Avenue

Cambridge, MA 02138

August 1986

The research reported here is part of the NBER's research program in Taxation. Any opinions expressed are those of the authors and not those of the National Bureau of Economic Research. 
Working Paper \#1994

August 1986

Taxation of Asset Income in the Presence of a World Securities Market

$\underline{\text { ABSTRACT }}$

This paper shows, using a standard CAPM model of security prices in a world market, that even small countries can affect the price of domestically issued risky securities, while large countries can affect the prices of all securities. As a result, countries have the incentive to set tax rates such that in equilibrium investors specialize in domestic securities, and net capital flows between countries are restricted. Each country does this to increase the utility of domestic residents, taking as given the tax policies of other governments, but the net outcome is a reduction in world efficiency and likely a reduction in the utility of all individuals.

Roger H. Gordon

Department of Economics

University of Michigan

Ann Arbor, MI 48109
Hal R. Varian

Department of Economics

University of Michigan

Ann Arbor, MI 48109 


\title{
TAXATION OF ASSET INCOME \\ IN THE PRESENCE OF A WORLD SECURITIES MARKET
}

\author{
by \\ Roger H. Gordon \\ University of Michigan and \\ National Bureau of Economic Research
}

and

Hal R. Varian

University of Michigan

Whenever a country is large enough to be able to affect the international price of a commodity that it trades in, then it will be tempted to set its policy so as to take advantage of this market power, at least so long as it can ignore any threat of retaliation by other countries. This observation forms the basis for a variety of results in the trade literature. For example, when a country can affect the price of its exported goods, then it will find tariffs or direct restrictions on exports attractive. ${ }^{1}$ Similarly, if a country is a net demander (supplier) of capital, and faces a nonhorizontal supply (demand) curve, then it may attempt to restrict its net demand (supply). ${ }^{2}$

The objective of this paper is to explore characteristics of government tax policy and equilibrium resource allocation when countries are not price-takers in the international market for financial securites. Due to risk aversion, the foreign demand for domestic securities should be downward sloping - foreign investors need more attractive terms to induce them to concentrate their portfolios further in any one security. Similarly, the supply curve of foreign securites should be upward sloping. The above observations suggest that each country would face the incentive to reduce both its net supply of domestic securities to foreigners and its net demand for foreign securities. When each country sets its policy accordingly, the net result will be restricted international trade in financial securities.

Since governments have much more market power than any one firm, it is not surprising that at least large countries should have an incentive to restrict international trade in financial securities. However, we show that each country continues to have market power over the price of the equity of domestic firms even as the number of countries becomes large, so that even small countries have the incentive to restrict foreign ownership of domestic 
equity. In contrast, only large countries have an incentive to restrict domestic ownership of foreign equity, or to restrict net capital flows.

This intervention can take many forms. Direct controls on the outflow of capital is obviously one device. To restrict foreign ownership of domestic equity, a dividend withholding tax on dividends sent to foreigners, or a dividend credit available only to domestic residents, can be used. In addition a corporate tax can be used to restrict the total supply of equity in the domestic firms. One way to restrict inflows of capital is to impose extra fees on multinational entrants to a country. Each of these policies is commonly observed, and each seems to us to be difficult to explain on other grounds.

Our results also provide one possible explanation for two empirical puzzles. The first is why individual portfolios are so highly concentrated in domestic securities. From a direct application of standard results in finance, one would expect investors to hold a fraction of the world portfolio of risky securities. ${ }^{3}$ Our model implies that governments have an incentive to induce investors to concentrate their portfolios in domestic equity.

The second puzzle, posed by Feldstein-Horioka(1980), is why net capital flows between countries are so small. Empirically, a country's savings and investment rates are very closely tied, even though these rates differ dramatically across countries. Our model implies that, at least in large countries, governments have an incentive to restrict net capital flows, to limit adverse movements in the interest rate.

Our analysis of optimal government policy, when a country is not a price-taker in the financial markets, is related to various aspects of the papers by Stiglitz(1972), JensenLong(1972), Ekern-Wilson(1974) and Leland(1974), which examine the optimal investment behavior of a firm which is not a price-taker in the financial market. We assume that asset prices satisfy the CAPM equation, as did Stiglitz and Jensen-Long. However, we also assume that the government acts in the best interests of its citizens, which relates more closely to the work by Ekern-Wilson and Leland, in which firms are assumed to act in the best interests of their shareholders.

The organization of the paper is as follows. In the next section, we describe the basic assumptions of our model, and then derive the characteristics of the market equilibrium in the face of arbitrary tax policy in each country. In section 2, we examine the Nash equilbrium for government policy when each government chooses its tax rates to maximize the welfare of its citizens, taking as given the tax policies of other governments. Since many complicated interaction effects can arise in general, we develop in this section a variety of special cases. In section 3, we provide a summary and discussion of the main results.

\section{Characteristics of the model}

\subsection{Behavior of individual consumers and individual firms}

Our economy consists of $N$ different countries, and operates for two periods. In each country $n$, there are $I_{n}$ identical individuals and $M_{n}$ identical firms. There is only one good in the economy, which is tradeable, which can be used in the first period for either consumption or investment, and which is entirely consumed in the second period. ${ }^{4}$ 
Each firm $f$ in country $n$ invests some amount of capital, $K_{f n}$, in the first period and produces a stochastic amount of output, $\theta_{n} F_{n}\left(K_{f n}\right)$, in the second period. Here, $F_{n}$ is a nonstoch astic (weakly) concave function, and $\theta_{n}$ is a normally distributed random variable with mean $\bar{\theta}_{n}$. The original capital is assumed to depreciate completely. This output, net of depreciation, is subject to a corporate income tax at rate $\tau_{n}$, but the resulting revenue is assumed to be returned to the firm in a lump-sum, $L_{f n}$, thereby avoiding any income effects from the tax. Therefore the firm's owners receive $R_{f n} \equiv \theta_{n} F_{f n}-\tau_{n}\left(\theta_{n} F_{f n}-K_{f n}\right)+L_{f n}=$ $\theta_{n} F_{f n}$ in the second period.

The firm in the first period "goes public" and sells shares of ownership in this return to individual investors. Denote the market value of these shares by $V_{f n}$, where $V_{f n}$ implicitly depends on the amount of capital $K_{f n}$ that the firm promises to acquire. The initial owners of the firm when it goes public then divide the residual $V_{f n}-K_{f n}$ among themselves. Since all firms in country $n$ are identical, we let $V_{n}=M_{n} V_{f n}$ denote their aggregate market value, $K_{n}=M_{n} K_{f n}$ denote their aggregate investment, and $R_{n}=M_{n} R_{f n}$ denote their aggregate return.

Before going public, each firm must decide how much capital it will promise to acquire. We assume that in doing so the firm maximizes the value of the residual $V_{f_{n}}-K_{f_{n}}$ going to its initial owners.

Each individual $i$ in country $n$ starts in the first period with wealth $W_{i n}$ and an initial ownership share $\bar{s}_{i n}^{m}$ in the firms in each country $m$. He must then decide how to divide these initial assets between first-period consumption, $C_{i n}^{1}$, final ownership shares, $s_{i n}^{m}$, and riskless bonds, $B_{i n}$. Riskless bonds pay an interest rate $r$, and the net supply of bonds in the world economy is zero. The individual decides on this division of his wealth subject to the budget constraint

$$
C_{i n}^{1}+B_{i n}+\sum_{m} s_{i n}^{m} V_{m}=W_{i n}+\sum_{m} \bar{s}_{i n}^{m}\left(V_{m}-K_{m}\right) .
$$

In the second period, he receives the income from his investments. However, any interest income is subject to tax at rate $t_{n}$, while any income from firms in country $m$ is subject to tax at rate $g_{m n} .{ }^{5}$ The resulting tax revenue is assumed to be returned to the individual by a lump sum transfer, $T_{i n}$, so that there are no income effects from the taxes, only price effects. Therefore, consumption in the second period, $C_{i n}^{2}$, must satisfy

$$
\begin{aligned}
C_{i n}^{2} & =\left(1+r\left(1-t_{n}\right)\right) B_{i n}+\sum_{m} s_{i n}^{m}\left(R_{m}-g_{m n}\left(R_{m}-V_{m}\right)\right)+T_{i n} \\
& =(1+r) B_{i n}+\sum_{m} s_{i n}^{m} R_{m}
\end{aligned}
$$

Individuals choose values for $C_{i n}^{1}$ and the various $s_{i n}^{m}$, allowing $B_{i n}$ to adjust according to the budget constraint, so as to maximize the utility function

$$
\begin{aligned}
U\left(C_{i n}^{1}, C_{i n}^{2}\right) & =-e^{-b_{n} C_{i n}^{1}}-\rho_{n} E e^{-b_{n} C_{i n}^{2}} \\
& =-e^{-b_{n} C_{i n}^{1}}-\rho_{n} e^{-b_{n}\left(E C_{i n}^{2}-\left(b_{n} / 2\right) \operatorname{var}\left(C_{i n}^{2}\right)\right)} .
\end{aligned}
$$


Here $b_{n}$ is the constant absolute risk aversion parameter, $\rho_{n}$ is a time preference parameter, and $E$ is an expectations operator. The second line of equation (3) follows since $C_{i n}^{2}$ is distributed normally. Assuming that the utility function has constant absolute risk aversion is obviously restrictive, but simplifies the following discussion significantly by allowing us to use mean-variance analysis with a constant trade-off between mean and variance.

The resulting first order conditions, after some simplification, can be expressed as

$$
\begin{gathered}
e^{-b_{n} C_{i n}^{1}}=\rho_{n}\left(1+r\left(1-t_{n}\right)\right) E e^{-b_{n} C_{i n}^{2}}, \quad \text { and } \\
E R_{m}=\left(1+\alpha_{m n} r\right) V_{m}+b_{n} \operatorname{cov}\left(R_{m}, C_{i n}^{2}\right),
\end{gathered}
$$

where, $\alpha_{m n}=\left(1-t_{n}\right) /\left(1-g_{m n}\right)$. Equation (4b) corresponds closely to the standard CAPM equation with taxes, as appears for example in Brennan(1970) or Gordon-Bradford(1980).

\subsection{Characteristics of the competitive equilibrium in the world economy}

The world economy is in equilibrium when each individual is maximizing utility given market prices, so equations (4a-b) are satisfied, when each firm has chosen that capital stock which maximizes the value of its residual claim, and when supply equals demand for each security. One useful characteristic of the resulting equilibrium can be derived by aggregating the equations (4b) across individuals for each security. In particular, if we divide equations (4b) for each individual by $b_{n}$ and sum across individuals, we get

$$
E R_{m} \sum_{n}\left(I_{n} / b_{n}\right)=\left[\sum_{n}\left(I_{n} / b_{n}\right)+r \sum_{n}\left(\alpha_{m n} I_{n} / b_{n}\right)\right] V_{m}+\operatorname{cov}\left(R_{m}, \sum_{n} I_{n} C_{i n}^{2}\right)
$$

This equation can be reexpressed, using equation (2), as

$$
E R_{m}=\left(1+\alpha_{m} r\right) V_{m}+B \operatorname{cov}\left(R_{m}, R\right)
$$

Here $B \equiv 1 /\left(\sum_{n}\left(I_{n} / b_{n}\right)\right)$ provides a measure of the degree of risk aversion of the market as a whole, $R \equiv \sum_{n} R_{n}$ measures the return on the market portfolio, and $\alpha_{m} \equiv$ $B \sum_{n}\left(\alpha_{m n} I_{n} / b_{n}\right)$ is a weighted average of the tax parameters faced by each individual in the economy, weighted by the inverse of each individual's degree of risk aversion, $b_{n}$. This equation is a simple generalization of the standard CAPM market line in a setting with taxes.

Each firm $f$ in each country $n$ chooses its capital stock to maximize the value of $V_{f n}-K_{f n}$, which implies that it chooses $K_{f n}$ such that $\partial V_{f n} / \partial K_{f n}=1$. The firm uses equation (5b) to forecast the impact of changes in its capital stock on its market value. We assume that the firm is small enough that in doing so it takes $\alpha_{m}, r, B$, and the return on the market portfolio, $R$, as given. Its optimal capital stock can therefore be characterized implicitly by

$$
\left(1-\tau_{n}\right) F_{n}^{\prime} \bar{\theta}_{n}+\tau_{n}=\left(1+\alpha_{n} r\right)+B \operatorname{cov}\left(\left(1-\tau_{n}\right) F_{n}^{\prime} \theta_{n}, R\right)
$$


This expression can be simplified using equation $(5 \mathrm{~b})$ to yield

$$
\frac{F_{n}^{\prime} V_{n}}{F_{n}}=1+\left(\frac{\tau_{n}}{1-\tau_{n}}\right)\left(\frac{\alpha_{n} r}{1+\alpha_{n} r}\right)
$$

The equation characterizing the equilibrium market interest rate can be derived in a similar fashion. Equation (4a) implies that

$$
\left(1 / b_{n}\right) \ln \left[\rho_{n}\left(1+\left(1-t_{n}\right) r\right)\right]=E C_{i n}^{2}-\left(b_{n} / 2\right) \operatorname{var} C_{i n}^{2}-C_{i n}^{1}
$$

But if we multiply each of the equations (4b) by $s_{i n}^{m}$ and sum over $m$, we find that

$$
b_{n} \operatorname{var} C_{i n}^{2}=E \sum_{m} s_{i n}^{m} R_{m}-\sum_{m} s_{i n}^{m}\left(1+\alpha_{m n} r\right) V_{m}
$$

Substituting equation (7b) into equation (7a), summing over all individuals, and using the budget constraints describing $C_{i n}^{1}$ and $C_{i n}^{2}$, we find that

$$
\sum_{n}\left(I_{n} / b_{n}\right) \ln \left[\rho_{n}\left(1+\left(1-t_{n}\right) r\right)\right]=.5 \sum_{m}\left[E R_{m}+V_{m}\left(1+\alpha_{m}^{*} r\right)\right]-\sum_{n}\left(I_{n} W_{i n}-K_{n}\right)
$$

where $\alpha_{m}^{*}=\sum_{n} s_{i n}^{m} I_{n} \alpha_{m n}$ represents the simple average of all the $\alpha_{m n}$ for each security. In this equation, the first term on the right-hand side simply measures the certainty equivalent amount of consumption in the second period while the second term measures first-period consumption.

\section{Characteristics of the Nash equilibrium for government tax policies}

While we have assumed that no individual and no firm is large enough to have any market power, each government could well be large enough to affect market prices through its tax policy. We assume that each government sets its tax rates so as to maximize the expected utility of its residents, taking into account any effect of its decisions on market prices. When a government considers what will happen to market prices, we assume that it takes as given the tax rates chosen by other governments, that it assumes all individuals and firms will continue to behave competitively, and that market prices will adjust so that all markets continue to clear. Other more complicated games between governments could be imagined, but this description of policy formulation seems to us to be quite reasonable.

Since taxes distort the allocation of resources, and any tax revenue is simply returned in a lump-sum fashion to whomever paid it, taxes will seem attractive only if they can be used to aid residents at the expense of nonresidents, through favorable changes in market prices. If a government assumes that market prices will continue to satisfy equation (5b), and that the parameters $\alpha_{m}, B, r$, and $R$, will all remain unaffected by any change in its own tax policy, then it follows quickly that the optimal tax rates are all zero. Without any taxes, residents in the country will choose that allocation which maximizes their utility 
given these assumptions about market prices, and competitive firms will act in the best interests of their shareholders under these assumptions.

However, when the government in some country $n$ uses its tax policy to change the domestic use of real resources, the various market prices must adjust so that individuals and firms in the other countries are just willing to accept the implied change in the resources available to them. Using the model described in section 1 , we can calculate the equilibrium market prices for any given use of resources in country $n$ by aggregating the first-order conditions (4a-b) across all nonresidents, holding fixed the resource use in country $n$. Following the same procedure that we used above, when we aggregated equation (4b) over all individuals, we find that

$$
E R_{m}=\left(1+\alpha_{m,-n} r\right) V_{m}+B_{-n} \operatorname{cov}\left(R_{m}, R-I_{n} C_{i n}^{2}\right)
$$

Here, $\alpha_{m,-n}=\left[\sum_{p \neq n}\left(I_{p} / b_{p}\right) \alpha_{m p}\right] /\left[\sum_{p \neq n}\left(I_{p} / b_{p}\right)\right]$ is a weighted average of the individual tax parameters, as before, but now averaged over all the nonresidents, while $B_{-n}=$ $1 /\left[\sum_{p \neq n}\left(I_{p} / b_{p}\right)\right]$ is the aggregate risk aversion parameter for the nonresidents. Note also that the appropriate market portfolio now equals the portfolio held by nonresidents. Similarly, if we aggregate equation (4a) over nonresidents, we find that

$$
\begin{aligned}
\sum_{p \neq n}\left(I_{p} / b_{p}\right) \ln \left[\rho_{p}(1+\right. & \left.\left(1-t_{p}\right) r\right]-.5 \sum_{m} E R_{m}\left(1-I_{n} s_{i n}^{m}\right)+(1+r) I_{n} B_{i n} \\
& -.5 \sum_{m}\left[1+\alpha_{m}^{*} r-I_{n} s_{i n}^{m}\left(1+\alpha_{m n} r\right)\right] V_{m}+\sum_{p \neq n} I_{p} C_{i p}^{1}=0 .
\end{aligned}
$$

When a government considers changing domestic real decisions, $K_{n}, C_{i n}^{1}$, and the $s_{i n}^{m}$, through its choice of tax rates, $\tau_{n}, t_{n}$, and the $g_{m n}$, it should therefore use equations (9ab) to forecast how market prices change. In doing so, it should also take into account how foreign firms revise their investment rates in response to changes in market prices, as described by equations (6b). The resulting implications for government policy are sufficiently complicated, however, that we will focus on a variety of special cases to shed light on what should happen in the general case.

\subsection{Market interest rates and foreign investment assumed fixed}

We begin by assuming that each government takes as given the market interest rate, $r$, and the amounts of capital, $K_{m}$, invested in the other countries, but otherwise uses equation (9a) to forecast the effects of its policies on asset values, $V_{m}{ }^{6}$ The government in each country $n$ therefore implicitly chooses $C_{i n}^{1}, K_{f n}$, and $s_{i n}^{m}$, to maximize the expected utility of its residents, taking into account what equation (9a) implies about asset prices, $V_{m}$.

Since the government takes the market interest rate as given, and so has no market power in the world bond market, it has no incentive to change the decisions residents make about how much to borrow or lend. Therefore, the desired tax rate on interest income, 
$t_{n}$, is zero. To show this, we differentiate expected utility with respect to $C_{i n}^{1}$, giving the first-order condition

$$
e^{-b_{n} C_{i n}^{1}}=\rho_{n}(1+r) E e^{-b_{n} C_{i n}^{2}} .
$$

(According to equation (9a), $C_{i n}^{1}$ has no effect on the $V_{m}$.) Comparing equations (4a) and (10), we find that individuals make the socially optimal decisions about $C_{\text {in }}^{1}$ only if $t_{n}=0$.

Equation (9a) does imply, however, that equity purchases by residents of country $n$ will have an effect on asset prices. Since residents do not take these effects into account, the desired tax treatment of equity income will be more complicated. The first-order conditions with respect to the government's implicit choice of the $s_{i n}^{m}$ are

$$
E R_{m}=(1+r) V_{m}+(1+r) I_{n} \sum_{p}\left(s_{i n}^{p}-\bar{s}_{i n}^{p}\right)\left(\partial V_{p} / \partial s_{i n}^{m}\right)+b_{n} \operatorname{cov}\left(R_{m}, C_{i n}^{2}\right)
$$

Here we find that to the extent that changing $s_{i n}^{m}$ raises the price of an asset for which the country is a net demander $\left(s_{i n}^{p}>\bar{s}_{i n}^{p}\right)$, the opportunity cost of buying a share in that asset, as measured by the right-hand side of equation (11), is increased. (A similar effect holds if the country is a net supplier of an asset.) Since individual portfolio choices are characterized by equations (4b), the government can induce individuals to make optimal portfolio choices by enacting tax rates on equity income from each asset such that

$$
\left(\alpha_{m n}-1\right) r V_{m}=(1+r) I_{n} \sum_{p}\left(s_{i n}^{p}-\bar{s}_{i n}^{p}\right)\left(\partial V_{p} / \partial s_{i n}^{m}\right)
$$

To see what happens to asset prices when domestic equity purchases change, we can differentiate equations (9a) with respect to $s_{i n}^{m}$ and find that

$$
\partial V_{p} / \partial s_{i n}^{m}=B_{-n} \operatorname{cov}\left(R_{p}, R_{m}\right) /\left(1+\alpha_{p,-n} r\right)
$$

When country $n$ purchases more of asset $m$, leaving less of this asset for nonresidents, the prices of those assets which are substitutes (have returns which covary positively with that on asset $m$ ) go up, and conversely.

Therefore, the government should discourage (encourage) ownership of any asset which is both a substitute (complement) for assets which the country demands on net and a complement (substitute) for assets which the country supplies on net. Government policy is in equilibrium when each country is simultaneously setting its tax policy according to equations (12) and (13).

In order to shed further light on the characteristics of this Nash equilibrium in government tax policy, we consider a special case in some detail. In particular, assume that each country is identical in all respects except that the random return on each country's technology is different. Assume, though, that $\operatorname{var}\left(R_{m}\right)=\sigma$ for all $m$, and that $\operatorname{cov}\left(R_{m}, R_{n}\right)=\nu$ for all $m \neq n$, where $\nu<\sigma$. In addition, assume that initially the equity in each country's firms is entirely owned by domestic residents, so that $\bar{s}_{i n}^{m}=0$ for $m \neq n$. 
Given this symmetry, we can describe a country's tax policy by the tax parameter used on income from the domestic security, $\alpha_{d}$, and the tax parameter used on any income from foreign securities, $\alpha_{f}$. Similarly, we can let $s_{d}$ represent the fraction of each firm owned domestically, and $s_{f}$ represent the fraction owned by investors in each foreign country. Since all shares must be owned, we know that $1-s_{d}=(N-1) s_{f}$. Other variables do not vary by country or by asset, so we drop subscripts unless they are needed for clarification.

Under these assumptions, the set of equations (12) describing equilibrium tax policy become

$$
\begin{aligned}
& \left(\alpha_{d}-1\right) r V=(1+r) I_{n} B\left[\frac{(N-1) s_{f} \nu}{\left(1+\alpha^{*} r\right)}-\frac{\left(1-s_{d}\right) \sigma}{\left(1+\alpha_{f} r\right)}\right], \quad \text { and } \\
& \left(\alpha_{f}-1\right) r V=(1+r) I_{n} B\left[\frac{s_{f}[(N-2) \nu+\sigma]}{\left(1+\alpha^{*} r\right)}-\frac{\left(1-s_{d}\right) \nu}{\left(1+\alpha_{f} r\right)}\right]
\end{aligned}
$$

where $\alpha^{*}=\left[(N-2) \alpha_{f}+\alpha_{d}\right] /(N-1)$ is a weighted average of the two tax parameters. Since $\sigma>\nu$, it follows by inspection that $\alpha_{f}>\alpha_{d}$. Therefore, the tax law will treat income from domestic securities more favorably than income from foreign securities. It is easy to show that $\alpha_{f}>1$. At least as long as $\sigma / \nu \geq(N-1) /(N-2)$, which we will assume, then also $\alpha_{d}<1$. Each country will discourage its residents from owning foreign securities, and encourage them to own domestic capital.

While each country subsidizes ownership of its domestic capital, foreign governments discourage their residents from owning this capital. On net, we find that ownership of capital will be discouraged, for if we examine the equilibrium tax parameter $\alpha_{m}$ in equation (5b) for each asset, we find that

$$
\alpha_{m}=1+\frac{(1+r) I_{n} B((N-1) \nu+\sigma)\left(1-s_{d}\right)}{r V}\left[\frac{1}{1+\alpha^{*} r}-\frac{1}{1+\alpha_{f} r}\right] .
$$

But since $\alpha^{*}<\alpha_{f}$, the term in brackets is positive and $\alpha_{m}>1$. The optimal tax policy therefore raises the required rate of return on equity, on net.

This use of tax policy to alter individual portfolios does not entirely disappear as the number of countries gets large. If we allow $N$ to increase, then in the limit it follows from equation (14b) that $\alpha_{f}=1$. However, also in the limit, we find that $\left(\alpha_{d}-1\right) r V=$ $I_{n} B\left(1-s_{d}\right)(\nu-\sigma)$, so that even as the number of countries increases, each country continues to push its residents to buy domestic equity. Each country remains large relative to the market for its own security, due to the fact that each country's security provides a unique source of diversification. However, in the limit, tax policy has no effect on market prices since in the limit $\alpha_{m}=1$.

In contrast to this example, if we assume instead that each country's initial ownership share in each technology also equals its desired final ownership share, so that $\bar{s}_{i n}^{m}=s_{i n}^{m}$ for all $m$, then equation (12) shows that the optimal value of $\alpha_{m n}$ equals one for all $m$ - no trade takes place in securities, so there is no gain from changing the price of 
any security. This setting is the one examined by Ekern-Wilson(1974) and Leland(1974) when investigating the investment behavior of firms. In general, our results show that the government faces an incentive to restrict international trade in securities. But if no trade would take place anyway, no intervention is needed to restrict trade further. The greater the trade that would take place without intervention, the larger are the optimal tax rates (in absolute value).

Given its use of taxes to distort individual portfolio decisions, the government will also find it desirable to distort the capital investment decisions of domestic firms. While domestic residents are subsidized to own domestic capital, given the amount invested, the capital investment decision should be made taking into account the full cost ignoring the subsidy. Therefore, to the extent that ownership is subsidized, the government should impose a corporate tax to offset this subsidy. Formally, the first-order condition with respect to $K_{f n}$ equals

$$
(1+r)\left[\bar{s}_{i n}^{n}+\sum_{m}\left(s_{i n}^{m}-\bar{s}_{i n}^{m}\right) \frac{\partial V_{m}}{\partial K_{f n}}\right]=\frac{s_{i n}^{n} F_{n}^{\prime}}{F_{n}}\left(E R_{n}-b_{n} \operatorname{cov}\left(R_{n}, C_{i n}^{2}\right)\right) .
$$

Using equation (9a) to calculate the changes in asset prices, and simplifying using equations (4b) and (12), finally gives

$$
\frac{F_{n}^{\prime} V_{n}}{F_{n}}=\frac{(1+r) I_{n} \bar{s}_{i n}^{n}}{(1+r) I_{n} \bar{s}_{i n}^{n}-r\left(1-\alpha_{n n}\right)}
$$

Comparing this equation with equation $(6 \mathrm{~b})$, we find that the optimal value of the corporate tax rate is characterized by

$$
\frac{1+\alpha_{n} r /\left(1-\tau_{n}\right)}{1+\alpha_{n} r}=\frac{(1+r) I_{n} \bar{s}_{i n}^{n}}{(1+r) I_{n} \bar{s}_{i n}^{n}-r\left(1-\alpha_{n n}\right)}
$$

Since $\alpha_{n n}<1$, we find that $\tau_{n}>0$. Therefore, capital investment is discouraged not only because $\alpha_{n}>1$ but also because of a supplementary corporate tax. Since $1-\alpha_{n n}$ remains positive even as $N$ grows without bound, we conclude that $\tau_{n}$ will also remain positive in the limit.

If $I_{n} \bar{s}_{i n}^{n}=1$, so that domestic firms are entirely owned domestically, the interpretation of the optimal value of $\tau_{n}$ is straight-forward, since equations (4b) and (15b) together imply that

$$
F_{n}^{\prime} \bar{\theta}_{n}=(1+r)+b_{n} \operatorname{cov}\left(F_{n}^{\prime} \theta_{n}, C_{i n}^{2}\right) \text {. }
$$

Tax policy has been designed so that the optimal amount of the domestic lottery, $\theta_{n}$, has been sold to foreigners. Any more of this lottery would be absorbed by domestic residents. As equation (16b) indicates, further investment in domestic capital is worthwhile until domestic residents are just indifferent between the return on this investment and the return from investing the same amount of resources in risk-free bonds. The corporate tax rate would then be set so as to just counterbalance the subsidy to domestic ownership of 
equity in domestic firms. But if $I_{n} \bar{s}_{i n}^{n}<1$, domestic investment should be cut back yet further since some of the loss from not maximizing $V_{n}-K_{n}$ is shared with nonresident initial owners.

If $I_{n} \bar{s}_{i n}^{n}<1$, then it is also the case that a country can seize a share of the residual claim $V_{n}-K_{n}$ owed to foreigners by imposing a cash-flow tax on the firm, and returning the resulting revenue not to the firm but to the domestic residents in a lump-sum. As many papers have shown, e.g. Boadway-Bruce(1984), such a tax has no effect on investment decisions, but raises as revenue a fraction of the true profits of the firm, which in our notation equal $V_{n}-K_{n}$.

\subsection{Endogenous foreign investment}

So far, each government has been assumed to take as given the amount of capital invested abroad when it decides on its tax policy. However, whenever asset prices change, the above model suggests that the amount of capital investment will change, and governments might be expected to foresee this. ${ }^{7}$ If they do, the above results change in a variety of ways.

Intuitively, when the government realizes that foreign investment can change, the perceived supply curve of foreign securities becomes more elastic. Previously, when a country purchased more foreign securities, the amount left for nonresidents decreased accordingly and its price went up. This increase in price, however, should lead foreign firms to invest more, attenuating the change in the amount of this lottery available to nonresidents, and therefore lessening the required change in the per unit price of the lottery. In fact, we show below that this increase in investment can be sufficient to lead the per unit price to fall.

Developing this argument in a general setting results in sufficiently complicated expressions that we instead examine the special case in which the production function has constant returns to scale, so that $F_{m}^{\prime \prime}=0$, in each country. Here, the investment response is maximized since there are no diminishing returns to inhibit this response. One interpretation of our previous analysis is that we assumed that $F_{m}^{\prime \prime}=-\infty$ in all countries, so that each firm's optimal capital stock is unchanged by policy actions.

Now that the amount available of each lottery can change, it will prove convenient to let $S_{i n}^{m} \equiv s_{i n}^{m} F_{m}$ represent the number of units purchased of the lottery from firms in country $m$, and let $v_{m} \equiv V_{m} / F_{m}$ represent the market price per unit of this lottery. Similarly, we define $\bar{S}_{i n}^{m} \equiv \bar{s}_{i n}^{m} F_{m}$. Using this notation, we assume that the government chooses values for $C_{i n}^{1}, \tau_{n}$, and the $S_{i n}^{m}$ to maximize the utility of the representative resident, given the effects of policy changes on the prices $v_{m}$.

In order to forecast how policy changes will affect $v_{m}$, the government in each country $n$ can conclude from equation $(6 \mathrm{~b})$ that

$$
v_{m}=\frac{1+\alpha_{m}^{r} /\left(1-\tau_{m}\right)}{\left(1+\alpha_{m} r\right) F_{m}^{\prime}} .
$$


Since $F_{m}^{\prime}$ is invariant given the constant returns to scale assumption, and since the government assumes $r$ is given, as are the $\tau_{m}$, for $m \neq n$, the only parameter that can affect $v_{m}$ is $\alpha_{m}$, which is a weighted average of the $\alpha_{m p}$ for all values of $p$ including $n$. Note that even $\alpha_{m}$ affects $v_{m}$ only if $\tau_{m} \neq 0$.

Since changes in $C_{\text {in }}^{1}$ still have no effect on asset prices, as seen in equation (17), it immediately follows that the optimal value of $t_{n}$ remains zero. However, each government can affect the value of its domestic firms' assets through $\tau_{n}$. As before, the government will wish to restrict the supply of the domestic security to drive up its price, and in this context will do so by imposing a corporate income tax. To see this, differentiate the utility of each resident with respect to $\tau_{n}$, holding $C_{i n}^{1}$ and the $S_{i n}^{m}$ fixed, yielding the first-order condition

$$
\bar{s}_{i n}^{n}\left(\frac{\partial V_{n}}{\partial \tau_{n}}-\frac{\partial K_{n}}{\partial \tau_{n}}\right)-S_{i n}^{n} \frac{\partial v_{n}}{\partial \tau_{n}}=0 .
$$

Using the definition of $v_{n}$ and equation (17), this can be reexpressed as

$$
\left(\bar{S}_{i n}^{n}-S_{i n}^{n}\right) \frac{\partial v_{n}}{\partial \tau_{n}}+\frac{\bar{s}_{i n}^{n} \tau_{n} \alpha_{n} r}{\left(1-\tau_{n}\right)\left(1+\alpha_{n} r\right)} \frac{\partial K_{n}}{\partial \tau_{n}}=0
$$

In order to learn how much $K_{n}$ will change, we need to use equation (9a) to solve for how much foreign purchases of domestic equity change in response to the change in the per unit cost of the domestic lottery, so how much extra capital must be invested to satisfy this change in demand. We find that

$$
\frac{\partial K_{n}}{\partial \tau_{n}}=-\frac{\left(1+\alpha_{n,-n} r\right)}{F_{n}^{\prime} B_{-n} \operatorname{var}\left(\theta_{n}\right)} \frac{\partial v_{n}}{\partial \tau_{n}} .
$$

Substituting equation (18c) into equation (18b) and simplifying gives

$$
\frac{\tau_{n}}{1-\tau_{n}}=\frac{\left(\bar{S}_{i n}^{n}-S_{i n}^{n}\right)\left(1+\alpha_{n} r\right) F_{n}^{\prime} B_{-n} \operatorname{var}\left(\theta_{n}\right)}{\bar{s}_{i n}^{n} \alpha_{n} r\left(1+\alpha_{n,-n} r\right)}
$$

As long as each country is a net supplier of the equity of its domestic firms, we conclude that each country will choose to impose a positive corporate income tax in order to drive up the price of domestic equity. Even as the number of countries grows without bound, each country will continue to use a corporate tax. This is because in the limit, as $N$ grows, we find that

$$
\frac{\tau_{n}}{1-\tau_{n}}=\left(\bar{S}_{i n}^{n}-S_{i n}^{n}\right) F_{n}^{\prime} B \operatorname{var}\left(\theta_{n}\right) /\left(\bar{s}_{i n}^{n} \alpha_{n} r\right) \text {. }
$$

The conditions characterizing the optimal values of the $S_{i n}^{m}$ also change considerably. Due to the change in notation, the first-order conditions become

$$
\bar{\theta}_{m}=(1+r) v_{m}+(1+r) I_{n} \sum_{p}\left(S_{i n}^{p}-\bar{S}_{i n}^{p}\right)\left(\partial v_{p} / \partial S_{i n}^{m}\right)+b_{n} \operatorname{cov}\left(\theta_{m}, C_{i n}^{2}\right) .
$$


As before, the second term on the right-hand side describes the effects arising from the market power of the country, which each individual would ignore. In order to calculate how each of the $v_{p}$ change, we first need to solve for the changes in the domestic tax rates $\alpha_{p n}$ needed to lead residents to change $S_{i n}^{m}$, holding everything else fixed. Differentiating the individual's first-order conditions $(4 \mathrm{~b})$, we find that

$$
\frac{\partial \alpha_{p n}}{\partial S_{i n}^{m}}=-\frac{b_{n}}{r v_{p}} \operatorname{cov}\left(\theta_{p}, \theta_{m}\right) \text {. }
$$

Given the definition of $\alpha_{p}$, we know that $\partial \alpha_{p} / \partial S_{i n}^{m}=\left(B I_{n} / b_{n}\right) \partial \alpha_{p n} / \partial S_{i n}^{m}$. Differentiating equation (17) with respect to $\alpha_{p}$, and using the above results, gives

$$
\frac{\partial v_{p}}{\partial S_{i n}^{m}}=-\frac{B I_{n} \tau_{p} \operatorname{cov}\left(\theta_{p}, \theta_{m}\right)}{\left(1+\alpha_{p} r\right)\left(1-\tau_{p}+\alpha_{p} r\right)}
$$

This equation indicates that purchasing more of a foreign asset, rather than raising its price and the price of substitute assets as before, now causes these prices to fall - the investment response of firms more than offsets the change in the amount purchased. This occurs since a cut in the tax rate domestic residents face on income from foreign equity, inducing them to purchase more foreign equity, makes it profitable according to equation (17) for foreign firms to invest until asset prices have been reduced.

When all countries are identical except for the differences in the $\theta_{m}$, the special case explored previously, then it is easy to show that $\alpha_{d}>1$ and $\alpha_{f}<1$. When the supply curve of foreign securities is downward sloping, the government should induce investors to buy more foreign securities in order to drive down the price, and conversely with respect to domestic securites. As a result, under these assumptions individual portfolios would be tilted towards ownership of foreign securites.

\subsection{Endogenous interest rate}

So far, we have assumed that the market interest rate is unaffected by policy changes, and so have implicitly assumed that aggregate savings is infinitely elastic with respect to the interest rate. This assumption is clearly unrealistic. ${ }^{8}$ In contrast, Jones(1967) assumed that the aggregate supply of capital was fixed when analyzing government policy with respect to capital location. In this section, we will point out briefly how optimal tax rates would change when market interest rates are endogenous, but foreign investment rates are again exogenous.

If changes in some policy instrument $x$ can affect market interest rates, then the firstorder conditions with respect to $x$ must include an extra term $(\partial U / \partial r)(\partial r / \partial x)$, to reflect the influence of domestic policy on market interest rates. This effect would be ignored by domestic residents. Let us therefore begin by examining $\partial U / \partial r$. Carrying out the differentiation, holding all policy instruments $\left(C_{i n}^{1}, K_{n}\right.$, and $\left.s_{i n}^{m}\right)$ constant but allowing the $V_{m}$ to respond, we find that

$$
\frac{\partial U}{\partial r}=\rho_{n} b_{n}\left[B_{i n}+(1+r) \sum_{m}\left(\bar{s}_{i n}^{m}-s_{i n}^{m}\right) \frac{\partial V_{m}}{\partial r}\right] E e^{-b_{n} C_{i n}^{2}} .
$$


We know from equation (9a) that $\partial V_{m} / \partial r=-\alpha_{m,-n} V_{m} /\left(1+\alpha_{m,-n} r\right)<0 .^{9}$ If we assume that $\alpha_{m,-n}=1$, as would be approximately true if $N$ were large, then the sign of $\partial U / \partial r$ equals the sign of $B_{i n}+\sum_{m}\left(s_{i n}^{m}-\bar{s}_{i n}^{m}\right) V_{m}=W_{i n}-C_{i n}^{1}-\sum_{m} \bar{s}_{i n}^{m} K_{m}$. Thus, $\partial U / \partial r>0$ if the country is a net supplier of funds to the world securities market, and conversely.

In order to judge how policy changes would affect market interest rates, a government is assumed to use equation ( $9 \mathrm{~b})$, which characterizes the market clearing interest rate, conditional on domestic policy choices. The main way in which the government can affect $r$ is presumably through changing the amount of domestic savings, or equivalently through changing first-period consumption. Using equation $(9 \mathrm{~b})$, we find that $\partial r / \partial C_{i n}^{1}=(2+$ r) $I_{n} / \Omega$, where $\Omega$ represents the partial derivative of the left-hand side of equation $(9 \mathrm{~b})$ with respect to $r$, holding all economic behavior constant, but taking into account the effects of $r$ on the other prices $V_{m}$. We assume that $\Omega>0$, so that $\partial r / \partial C_{i n}^{1}>0$. This implies that the interest rate must be higher in order for nonresidents to be willing to consume less in the first period and more in the second period. Therefore, the effect of first-period consumption on market interest rates makes first-period consumption more attractive when the country is a net supplier of funds, and less attractive when the country is a net demander of funds. As a result, tax policy should be used to restrict the absolute size of capital flows. ${ }^{10}$ Therefore, interest income should be taxed when the country is a net supplier of funds, in order to make lending less attractive. Similarly, interest income should be subsidized to increase the cost of borrowing from abroad if the country is a net demander of funds. ${ }^{11}$

Calculating the effects of either $K_{n}$ or $s_{i n}^{m}$ on market interest rates leads to sufficiently complicated expressions that we omit them from the paper. However, these expressions suggest that an increase in investment, holding own savings constant, would require a rise in interest rates. Similarly, if $s_{i n}^{m}$ is increased, nonresidents must be content holding more bonds and less equity which should require a rise in the interest rate. Therefore, if the country is a net demander (supplier) of capital, investments in both real capital and in equity are less (more) attractive due to their effects on market interest rates. Therefore, everything else equal corporate tax rates and tax rates on equity income should be higher (lower) if the country is a net demander (supplier) of capital.

However, as the number of countries gets large, equation (9b) indicates that each country has less and less effect on market interest rates. Therefore, these additional complications disappear in the limit as the number of countries grows.

\section{Conclusions}

This paper has shown that whenever a country is not a price-taker in the international securities market, then it has an incentive to design its tax policy so as to restrict international trade in these securities. For example, as a number of writers have argued, if a country can affect the prevailing market interest rate through its net demand or supply of funds, then it has an incentive to restrict the size of this net demand or supply. In fact, Summers (1985) has argued that governments do indeed use their fiscal policies to restrict their net demand or supply of funds, or equivalently to restrict the difference between their savings rate and their investment rate. This use of market power may therefore 
provide one explanation for the observation by Feldstein-Horioka(1980) that among the O.E.C.D. countries, the difference between a country's savings rate and investment rate tends to be small. ${ }^{12}$ We show, however, that this incentive to restrict the net flow of funds is smaller for smaller countries. Indeed the evidence reported in both Summers(1985) and Obstfeld(1985) is that the savings and investment rates for smaller countries are much less closely tied than are those for larger countries.

In addition, we show that each country faces the incentive to restrict the amount of equity in its domestic firms owned by foreigners and the amount of equity in foreign firms owned by domestic residents. It can do so both by imposing a corporate tax on its domestic firms, to restrict the total supply of their equity, and by imposing a set of taxes on the income its residents receive from equity, to induce them to concentrate their portfolios in domestic equity. ${ }^{13}$ This use of market power may therefore also help explain the very limited degree of international diversification that is observed empirically.

More surprisingly, we show that even small countries have the incentive to restrict the supply of domestic equity available to foreigners, both by reducing the total supply of domestic equity through a corporate income tax and also by reducing the fraction of this total supply available to foreigners by inducing domestic residents to concentrate their portfolios in domestic equity. These results on the design of tax policy in a small open economy are in sharp contrast to those in Gordon(forthcoming), who examined optimal tax policies in a similar model but without uncertainty. Without uncertainty, small countries are price-takers and should not distort corporate investment decisions or individual portfolio decisions even when other sources of tax revenue impose efficiency costs.

As in models of tariff policy, we find that each country, acting in isolation, faces an incentive to distort the allocation of resources (and of risk-bearing) in order to take advantage of its market power. The net result may well be a loss in utility in all countries - if all countries are identical (except for the risk characteristics of domestic production), this is certainly the case. Just as binding agreements to avoid using tariffs (such as GATT) should raise the efficiency of the allocation of resources, binding agreements on tax policy should also be attractive. Unlike the case of tariffs, however, governments normally wish to tax savings and investment independently of attempts to exploit market power in international securities markets. Therefore, formulating an agreement which prevents governments from taking advantage of their market power in the financial securities markets and yet which leaves them adequate flexibility in the design of domestic tax policy may be very difficult.

In deriving these results, we have used a somewhat specialized model. In particular, we have assumed that individuals have constant absolute risk aversion, that all security returns are distributed normally, that there are only two periods, and that there is only one physical commodity. Together, these assumptions allow us to use a standard variant of the CAPM model of securities prices. The assumptions also imply that purchasing power parity prevails. ${ }^{14}$ Each of these assumptions clearly simplifies the algebra, but we see no reason that these simplifications should change any of the qualitative conclusions from the model. 


\section{REFERENCES}

Adler, Michael and Bernard Dumas. "International Portfolio Choice and Corporation Finance: A Synthesis." Journal of Finance 38(June, 1983): 925-984.

Boadway, Robin and Neil Bruce. "A General Proposition on the Design of a Neutral Business Tax." Journal of Public Economics 24(1984): 231-239.

Brennan, Michael J. “Taxes, Market Valuation and Corporate Financial Policy.” National Tax Journal 23(1970): 417-427.

Ekern, Steinar and Robert Wilson. "On the Theory of the Firm in an Economy with Incomplete Markets.” Bell Journal of Economics 5(Spring, 1974): 171-80.

Feldstein, Martin S. and David Hartman. "The Optimal Taxation of Foreign Source Investment Income." Quarterly Journal of Economics 93(November 1979): 613-29.

Feldstein, Martin S. and Charles Horioka. "Domestic Savings and International Capital Flows. The Economic Journal 90(1980): 314-329.

Gehrels, Franz. "Optimal Restrictions on Foreign Trade and Investment." American Economic Review 61(1971): 147-159.

Gordon, Roger H. 'Discussion of 'Taxation and International Competitiveness' by Lawrence H. Summers". Mimeo, Dec., 1985.

- "Taxation of Investment and Savings in a World Economy." American Economic Review, forthcoming.

Gordon, Roger H. and David F. Bradford. "Taxation and the Stock Market Valuation of Capital Gains and Dividends." Journal of Public Economics 14(1980): 109-136.

Hartman, David G. "On the Optimal Taxation of Capital in the Open Economy." N.B.E.R. Working Paper No. 1550, $1985 \mathrm{a}$.

"The International Financial Market and U.S. Interest Rates." Journal of International Money and Finance 3(April, 1984): 91-103.

“The Welfare Effects of a Capital Income Tax in an Open Economy." N.B.E.R. Working Paper No. 1551, 1985b.

Jensen, Michael C. and John B. Long, Jr. "Corporate Investment Under Uncertainty and Pareto Optimality in the Capital Markets." Bell Journal of Economics 3(Spring, 1972): 151-74.

Jones, Ronald W. "International Capital Movements and the Theory of Tariffs and Trade." Quarterly Journal of Economics 81(February, 1967): 1-38.

Leland, Hayne E. "Production Theory and the Stock Market." Bell Journal of Economics 5(Spring, 1974): 125-44. 
Obstfeld, Maurice. "Capital Mobility in the World Economy: Theory and Measurement.” N.B.E.R. Working Paper No. 1692, August, 1985.

Stiglitz, Joseph E. "On the Optimality of the Stock Market Allocation of Investment." Quarterly Journal of Economics 86(February, 1972): 25-60.

Summers, Lawrence H. “Taxation and International Competitiveness.” Mimeo, March, 1985. 


\section{FOOTNOTES}

* We would like to thank participants in a seminar at N.B.E.R., and especially Richard Clarida, for comments on a previous draft. The views expressed in this paper are those of the authors and not necessarily those of N.B.E.R.

1. The most obvious example of such export restrictions is OPEC.

2. See, for example, Jones(1967), Gehrels(1971), Feldstein-Hartman(1979), or Hartman(1985ab), for further discussion. When a country has market power in both the capital market and the commodity market, as in Jones and Gehrels, interaction effects add complications.

3. Adler-Dumas(1983) show empirically that, even taking exchange rate risk into account, the mean-variance efficient portfolio for an investor can be approximated by a combination of nominally risk-free domestic bonds and a share of the world portfolio in equity.

4. We therefore assume purchasing power parity. For a related discussion of use of government policy to take advantage of market power with respect to exchange rates, see Gordon(1985).

5. Existing tax structures do not normally differentiate directly between income from foreign and domestic securities. However, a number of countries impose a dividend withholding tax on dividends from domestic firms paid to foreigners. If $R_{m}$ is defined to equal what foreigners receive on equity, then a withholding tax is equivalent to a subsidy on ownership of domestic equity. Similarly, a number of countries have a dividend credit which is available only to domestic residents on equity of domestic firms. The ability of governments to differentiate between income from different foreign countries is assumed to simplify the notation in the following discussion.

6. These assumptions correspond to those used by Stiglitz(1972) and Jensen and Long(1972) in analyzing the behavior of a firm which is not a price-taker in the securities market.

7. Since this response will be more gradual than the response of equity prices to policy changes, forecasting its size would be far more difficult, however.

8. See, for example, Hartman(1984).

9. If, in contrast, we assumed that investment rates were endogenous, and production functions were linear, then this derivative would change sign as well as form.

10. See Jones(1967), Hartman(1985b), and Feldstein-Hartman(1979) for similar results. 
11. There could also be an incentive to use government budget deficits (surpluses) to reduce the country's net supply (demand) of capital. In the above model, however, government fiscal policy would have no real effects.

12. The model does not provide support, however, for the inference by FeldsteinHorioka that extra domestic savings leads to essentially the same amount of extra domestic investment. Given our assumption of constant absolute risk aversion, at the margin any extra savings in a country, holding its tax policy constant, is used to buy risk-free bonds, and so results in a drop in the world interest rate and an equivalent expansion in investment in all countries.

13. This last result can change if the amount of capital investment by firms is sufficiently elastic with respect to the market value of its equity.

14. For a related argument concerning the incentives a country faces when it can influence currency exchange rates, in a model without uncertainty, see Gordon(1985). 